\title{
A Fuzzy AHP Model for Selection of University Academic Staff
}

\author{
Daniel E. Asuquo \\ Dept. of Computer Science University of Uyo \\ PMB 1017, 520003, Uyo \\ Nigeria
}

\author{
Friday E. Onuodu \\ Dept. of Computer Science University of Port \\ Harcourt \\ PMB 5323, Port Harcourt \\ Nigeria
}

\begin{abstract}
There is a growing interest in university academic staff selection since the quality of staff has a direct influence on any organization's effectiveness. The process of selecting suitable academic staff for employment is complex and involves taking multiple criteria into consideration for good decision making. Analytic Hierarchy Process (AHP) is a Multi-Criteria Decision Making (MCDM) model for dealing with decision making problems affected by several conflicting factors. It is useful for selecting the best among alternatives based on certain criteria. However, academic staff selection also contains uncertainties which pose another problem, since the AHP lacks the ability to deal with imprecise and subjective judgment in its pair-wise comparison process. This problem can be overcome by the use of AHP model with fuzzy logic, called Fuzzy AHP model, where triangular fuzzy numbers (TFNs) and linguistic variables are used to achieve better accuracy and consistency in the decision makers' (DM) judgment. A system architecture is developed for problem solving using this model. This paper uses Chang's synthetic extent analysis with TFNs to improve human experts' decision making when recruiting by generating a range of values to incorporate DMs' uncertainty, instead of a crisp value. Numerical example using three alternative candidates based on these criteria: work experience, academic background, and individual skill is presented. The result indicates that the alternative with the highest normalized weight is the most suitable candidate to be selected for employment. This work could be very useful to university establishment and to any other organization that may be interested in fair and efficient recruitment exercise.
\end{abstract}

\section{General Terms}

Fuzzy Logic, Decision Making

\section{Keywords}

MCDM, Staff Selection Process, Fuzzy AHP, Triangular Fuzzy Numbers \& Synthetic Extent Analysis

\section{INTRODUCTION}

The recent increase in the number of public and private universities in Nigeria demands a more proactive approach to the selection of suitable academic staff for employment. Staff selection process is aimed at determining those candidates with requisite up-to-date knowledge, work experience, research quality, and communication skills for recruitment [1]. In any organization, personnel selection is one responsibility of human resources management (HRM) which is seen as a complex task involving the consideration of multiple criteria for good decision making. Multiple criteria decision making (MCDM) refers to making a decision in the presence of multiple and often conflicting criteria. In [2], it is seen as an approach that makes use of a set of techniques for providing an overall ordering of options from the most preferred to the least preferred option to help decision makers (DMs) choose the most desirable and satisfactory alternative under uncertain situation. MCDM is classified into Multi Objective Decision Making (MODM) and Multi Attribute Decision Making (MADM). MODM deals with multi objective planning problems when a theoretically infinite number of continuous alternatives are defined by a set of constraints on a vector of decision variables while MADM methods are designed for selecting discrete alternatives [3]. A typical MADM problem is formulated in [4] as:

$$
\begin{aligned}
& \text { select } A_{i} \text { from } A_{1}, A_{2}, \ldots, A_{m} \\
& \text { using } C_{1}, C_{2}, \ldots, C_{n}
\end{aligned}
$$

where $\left\{A_{1}, A_{2}, \ldots, A_{m}\right\}$ denotes $m$ alternatives and $\left\{C_{1}, C_{2}\right.$, $\left.\ldots, C_{n}\right\}$ represents $n$ criteria.

The Analytic Hierarchy Process (AHP), Multi Attribute Utility Theory (MAUT) and Outranking methods are the most frequently applied MADM methods to discrete decision problems. To solve these problems will require the construction of an evaluation procedure to rate and rank a set of alternatives in order of preference. AHP mathematically handles multi-criteria decision making through pair-wise comparison of DMs' subjective judgment of criteria and alternatives with respect to the goal. Although both quantitative and qualitative data can be handled by AHP, it however cannot handle the imprecision, uncertainties, fuzziness and vagueness that exist in academic staff selection process by decision makers [5]. According to [6], the uncertainties in human preference can be modeled by incorporating fuzzy logic with the pair-wise comparison. This is called Fuzzy AHP (FAHP) model. This MCDM approach allows a more accurate description of the decision making process. Researches abound on the application of this method to problem solving in various scientific and management fields such as company's inventory control and classification [5], selection of measuring instrument for undergraduate engineering institution [6], water quality management [7], hydrogeology groundwater management [8], network prenegotiation service evaluation [9], measurement of objectoriented software usability [10] and personnel selection in HRM [11].

The authors in [5] only compared AHP and FAHP models in determining which criteria has higher priority than others in inventory classification. However, pair-wise comparison of alternatives based on given criteria was not performed. In [11], only personality, leadership and past experience, general aptitude, and comprehension were considered as criteria for candidates' ranking for personnel selection. In a university establishment, selecting candidates for a teaching appointment requires consideration of academic qualifications, research and teaching experience, compatibility, general aptitude as well as good expression in English. Furthermore, the selection 
process was modified in [1] by combining the upper and lower limit values of the triangular fuzzy numbers with an optimism index $(\lambda)$ and the use of a fuzzy conversion scale with less emphasis on intermediate values. This paper describes an application of multi-criteria fuzzy optimization technique called FAHP, to select the most suitable candidate for academic staff employment. In this approach, pair-wise comparison scale is handled based on triangular fuzzy numbers (TFNs) followed by the use of extent analysis method where synthetic extent values are used to obtain priority weights. The fuzzy evaluation matrix of the criteria is constructed through the pair-wise comparison of different attributes relevant to the overall objective using the linguistic variables and TFNs.

This paper presents a more advanced analytical method to improve decision making on staff selection. The rest of the paper is organized as follows: Section 2 discuses the structure and major steps of the classical AHP method for a multicriteria problem solving. The popular Saaty preference scale for pair-wise comparison is also presented with a note on the shortcomings of AHP. In section 3, the proposed fuzzy AHP model is presented with its TFNs, fuzzy conversion scale, the linguistic variables and membership functions of a TFN. Section 4 gives the steps considered in Chang's extent analysis method to evaluate the TFNs and the methods used in obtaining normalized priority weights of criteria and alternatives needed to achieve the goal in the decision hierarchy. The developed system architecture for solving a problem using FAHP model is presented along with numerical examples. Section 5 discusses the results while section 6 summarizes and concludes the paper.

\section{CLASSICAL AHP METHOD}

All AHP is a useful mathematical method for solving MCDM problems, where a choice has to be made from a number of alternatives based on their relative importance. It relies on the judgments of experts to derive priority scales through pairwise comparison of decision elements at each level of the built hierarchy. It enables the development of numerical score or weight to rank each decision alternative based on given criteria and the computation of consistency ratio to determine the reliability of the comparative judgments represented in the comparison matrix. The mathematical formulas needed to form comparison matrix, determine weights, consistency ratio, and make final ranking for decision making can be found in [12]. Figure 1 shows the structure of the AHP method while Table 1 presents the nine-point preference scale used for pair-wise comparison. The application of the AHP method to a MCDM problem usually involves these five major steps described in [13]-[14]:

i. Define the unstructured problem by describing the hierarchy with the goal at the top, followed by criteria at the lower levels and then alternatives at the bottom.

ii. Construct a set of pair-wise comparison matrices among decision elements $i$ and $j$ by establishing priorities among them based on a preference scale.

iii. Compute the consistency ratio to determine the acceptability or otherwise of the chosen criteria or alternative.

iv. Estimate the relative weights of the decision elements using eigenvector method. v. Aggregate these relative weights and synthesize them for the final measurements of the decision alternatives.

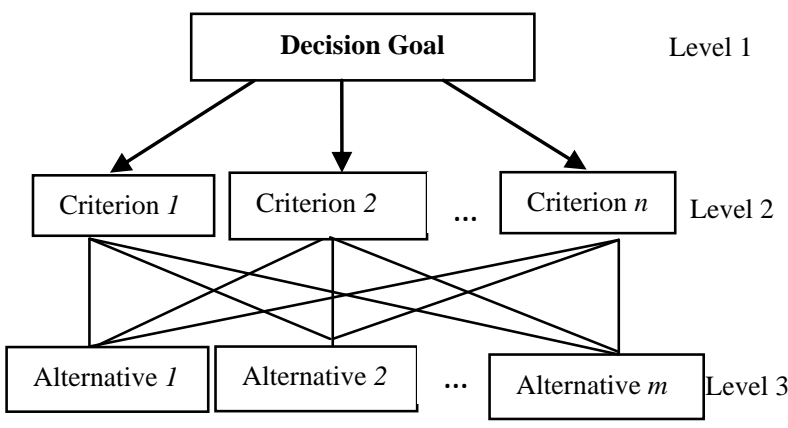

Fig 1: Structure of AHP

Table 1. AHP preference scale for pair-wise comparison

\begin{tabular}{|l|l|}
\hline \multicolumn{1}{|c|}{$\begin{array}{c}\text { Importance } \\
\text { Scale }\end{array}$} & \multicolumn{1}{c|}{ Description } \\
\hline 1 & $i$ and $j$ are equally important \\
3 & $i$ is moderately more important than $j$ \\
5 & $i$ is strongly more important than $j$ \\
7 & $i$ is very strongly more important than $j$ \\
9 & $i$ is extremely more important than $j$ \\
$2,4,6,8$ & $\begin{array}{l}\text { Intermediate values when a } \\
\text { compromise is needed a }\end{array}$ \\
\hline
\end{tabular}

The work in [5] reveal that the subjective judgment, selection and preference of DMs have significant influence on the AHP results since the method does not consider the uncertainty involved in such comparative judgment. Furthermore, the method gives crisp values for decision making and the ranking is rather imprecise. Thus, Fuzzy AHP model is proposed to reflect DMs uncertain preferences through crisp values. The Fuzzy Set Theory (FST) introduced by Zadeh in [15]-[16] to deal with uncertainty and vagueness allows mathematical operators and programming to be performed on the fuzzy domain. The basic unit that represents knowledge in fuzzy logic is a linguistic variable, with its linguistic values that make up fuzzy sets. The set is characterized by a membership function, which assigns to each object a grade of membership ranging between " 0 " and " 1 " [17]. The linguistic or fuzzy variables have a quantified analytical formmembership function, such that they are of dual nature. This dual identity makes linguistic variables suitable for qualitative-symbolic and quantitative-numerical calculations. A correlation is thereby established between the natural language used by human and the numerical data used by a computer.

\section{FUZZY AHP MODEL}

The fuzzy AHP technique, which is an analytical extension of the classical AHP method, uses fuzzy comparison ratios described by triangular membership functions to handle the uncertainties inherent in the AHP method. The idea is to use triangular fuzzy numbers (TFNs) to express the weights of the nine level scales of judgment in order to represent the relative importance among the hierarchy's criteria [18]. A TFN, M denoted by a triple of real numbers $(\mathrm{l}, \mathrm{m}, \mathrm{u})$ is shown in figure 2 , with parameters $\mathrm{l} \leq \mathrm{m} \leq \mathrm{u}$ where $\mathrm{l}$ indicates the smallest possible value, $\mathrm{m}$ is the most promising value, and $\mathrm{u}$ indicates the largest possible value of the membership function $\mu_{\mathrm{M}}(\mathrm{x})$. Figure 3 shows the linguistic variables used to express the 
importance of each criterion. The membership function of a TFN is given in equation 2 as:

$\mu_{M}(x)= \begin{cases}\frac{x-l}{m-l}, & l \leq x \leq m \\ \frac{u-x}{u-m}, & m \leq x \leq u \\ 0, & \text { otherwise }\end{cases}$

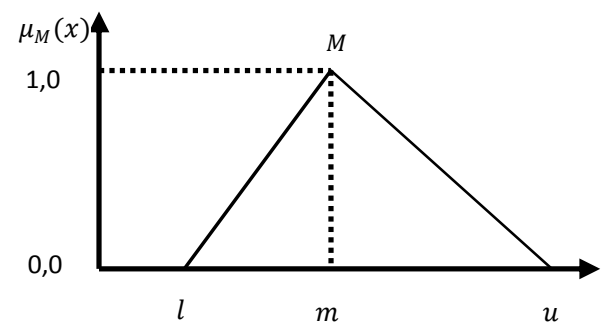

Fig 2: A triangular fuzzy number, $M$

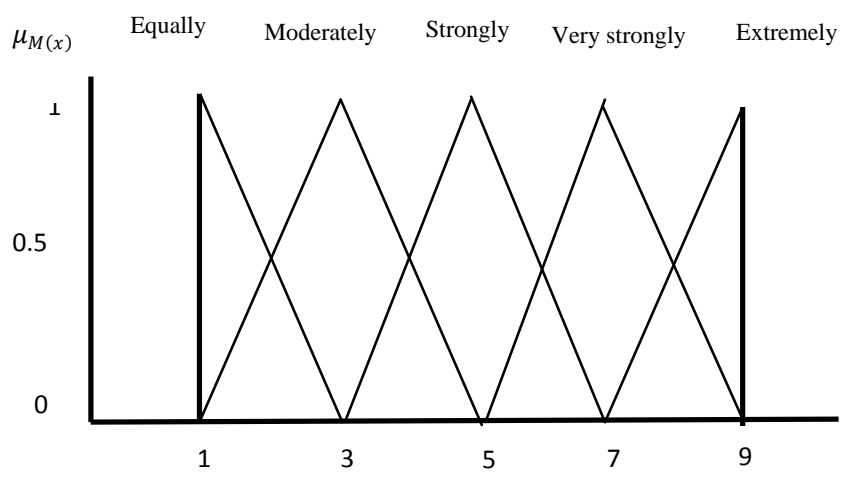

Fig 3: Linguistic variables for the importance weight of criteria

Methods proposed for attaining normalized priorities in the FAHP method are found in literature. These include the first initiated study that applied fuzzy logic with AHP which involves the use of (i) fuzzy numbers with triangular membership function [19] to express the evaluation of the DM of alternatives against each of the given criteria, (ii) geometric mean method with trapezoidal membership function [20] for the same purpose, (iii) FAHP scale, TFNs and synthetic extent analysis method [21] to compare pairs of criteria in a matrix, (iv) fuzzy least squares method [22], (v) fuzzy preference programming [23], and (vi) two-stage logarithmic programming [24].

In this paper, priorities estimation for selecting the best candidate for academic staff employment is accomplished using the synthetic extent analysis method by Chang in [21]. Chang's extent analysis on FAHP depends on the degree of possibility of superiority of each criterion. Firstly, the method uses TFNs for pair-wise comparison by means of FAHP scale proposed in [13]. Thereafter, the extent analysis method is adopted to obtain priority weights by using synthetic extent values. The fuzzy evaluation matrix of the criteria is formed through pair-wise comparison of different attributes relevant to the overall objective. The fuzzified Saaty's scale in [21], [24]-[25] is used to represent the correlation between the numerical values of TFNs and linguistic variables. One such correlation is shown in Table 2, where the reciprocal of the TFN, $M_{i}^{-1}$ is denoted as $\left(\frac{1}{u_{i}}, \frac{1}{m_{i}}, \frac{1}{l_{i}}\right)$.
Table 2. Fuzzified Saaty's scale for pair-wise comparison

\begin{tabular}{|l|c|l|c|}
\hline \multicolumn{1}{|c|}{$\begin{array}{c}\text { Linguistic } \\
\text { Variable }\end{array}$} & $\begin{array}{c}\text { Fuzzy } \\
\text { Number } \\
\text { (or crisp } \\
\text { value) }\end{array}$ & $\begin{array}{l}\text { FAHP Scale } \\
\text { TFN }(\boldsymbol{l}, \boldsymbol{m}, \boldsymbol{u}) \\
(0.5 \leq x \leq 0.5)\end{array}$ & $\begin{array}{l}\text { Reciprocal of } \\
\text { TFN }\end{array}$ \\
\cline { 1 - 3 } Just equal & \multirow{2}{*}{$\begin{array}{l}\text { Equally } \\
\text { important }\end{array}$} & $(1,1,1)$ & $(1,1,1)$ \\
\cline { 3 - 5 } $\begin{array}{l}\text { Moderately } \\
\text { important }\end{array}$ & 3 & $(1,1,1+x)$ & $\left(\frac{1}{1+x}, 1,1\right)$ \\
\hline $\begin{array}{l}\text { Strongly } \\
\text { important }\end{array}$ & 5 & $\left(5-x, 5,5,3, \frac{1}{3+x}, \frac{1}{3-x}\right)$ & $\left(\frac{1}{5+x}, \frac{1}{5}, \frac{1}{5-x}\right)$ \\
\hline $\begin{array}{l}\text { Very strongly } \\
\text { important }\end{array}$ & 7 & $(7-x, 7,7+x)$ & $\left(\frac{1}{7+x}, \frac{1}{7}, \frac{1}{7-x}\right)$ \\
\hline $\begin{array}{l}\text { Extremely } \\
\text { preferred }\end{array}$ & 9 & $(9-x, 9,9)$ & $\left(\frac{1}{9}, \frac{1}{9}, \frac{1}{9-x}\right)$ \\
\hline $\begin{array}{l}\text { Intermediate } \\
\text { values }\end{array}$ & $2,4,6,8$ & $(x-1, x, x+1)$ & $\left(\frac{1}{x+1}, \frac{1}{x}, \frac{1}{x-1}\right)$ \\
\hline
\end{tabular}

\section{MODEL DESCRIPTION WITH CHANG'S EXTENT ANALYSIS}

Given a set of criteria and a set of goal, each criterion is taken and Chang's extent analysis for each goal is performed, respectively. In the academic staff selection problem using FAHP technique, the extent analysis method is applied on the TFNs. According to [21], [27] and [28], the steps for the Chang's extent analysis can be summarized as follows:

Step 1:

The criteria that affect the selection of one among several alternatives are defined, and a matrix of criterion $C$ is constructed with TFNs assigned by the DM (expert) using FAHP scale.

Step 2:

With the generated matrix, an extent analysis of all the elements of the matrix is conducted, resulting in $m$ values of steps analysis for each element of the set $C$ as follows:

$M_{g_{i}}^{1}, M_{g_{i}}^{2}, M_{g_{i}}^{3}, \ldots, M_{g_{i}}^{m}$, where $g_{i}(i=1,2,3, \ldots, n)$ is the goal set and all the $M_{g_{i}}^{j}(j=1,2,3, \ldots, m)$ are TFNs. Then, taking into account the membership function of the TFNs, the fuzzy synthetic extent value $\left(S_{i}\right)$ with respect to the $i_{t h}$ criteria is defined by equation (3) as:

$S_{i}=\sum_{j=1}^{m} M_{g_{i}}^{j} \otimes\left[\sum_{i=1}^{n} \sum_{j=1}^{m} M_{g_{i}}^{j}\right]^{-1}$

where $\sum_{j=1}^{m} M_{g_{i}}^{j}$ is obtained as in equation (4) by performing fuzzy addition operation on $m$ extent analysis values for a particular matrix such that:

$\sum_{j=1}^{m} M_{g_{i}}^{j}=\left(\sum_{j=1}^{m} l_{j}, \sum_{j=1}^{m} m_{j}, \sum_{j=1}^{m} u_{j}\right)$

The end of that computation yields a new set of $(l, m, u)$ which is used to obtain $\left[\sum_{i=1}^{n} \sum_{j=1}^{m} M_{g_{i}}^{j}\right]^{-1}$ by performing fuzzy addition operation of $M_{g_{i}}^{j}(j=$ $1,2,3, \ldots, m$ ) values such that:

$\sum_{i=1}^{n} \sum_{j=1}^{m} M_{g_{i}}^{j}=\left(\sum_{i=1}^{n} l_{i}, \sum_{i=1}^{n} m_{i}, \sum_{i=1}^{n} u_{i}\right)$

And then compute the inverse of the vector in equation (5) to obtain equation (6) as follows: 


$$
\left[\sum_{i=1}^{n} \sum_{j=1}^{m} M_{g_{i}}^{j}\right]^{-1}=\left(\frac{1}{\sum_{i=1}^{n} u_{i}}, \frac{1}{\sum_{i=1}^{n} m_{i}}, \frac{1}{\sum_{i=1}^{n} l_{i}}\right)
$$

Step 3:

The degree of possibility of two TFNs $M_{2}=\left(l_{2}, m_{2}, u_{2}\right)$ and $M_{1}=\left(l_{1}, m_{1}, u_{1}\right)$ is defined by equation (7) as:

$V\left(M_{2} \geq M_{1}\right)=\sup \left[\min \left(\mu_{M 1}(x), \mu_{M 2}(y)\right)\right], \quad y \geq x$

where $x$ and $y$ are the values on the axis of membership function of each criterion. The expression can be conveniently written by equation (8) as follows:

$$
\begin{aligned}
& V\left(M_{2} \geq M_{1}\right)=h g t\left(M_{1} \cap M_{2}\right)= \\
& \begin{cases}1, & \text { if } m_{2} \geq m_{1} \\
0, & \text { if } l_{1} \geq u_{2} \\
\frac{l_{1}-u_{2}}{\left(m_{2}-u_{2}\right)-\left(m_{1}-l_{1}\right)}, & \text { otherwise }\end{cases}
\end{aligned}
$$

where, according to [18], $d$ is the ordinate of the highest intersection point $D$ between the membership functions $\mu_{M 1}$ and $\mu_{M 2}$ as depicted in figure 4. To compare the TFNs $M_{1}$ and $M_{2}$, both the values of $V\left(M_{1} \geq M_{2}\right)$ and $V\left(M_{2} \geq M_{1}\right)$ are needed.

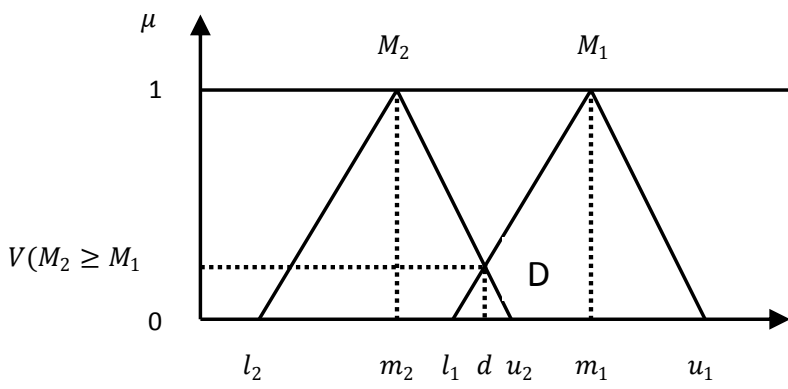

Fig 4: Intersection between $\mu_{M 1}$ and $\mu_{M 2}$

The degree of possibility for a convex fuzzy number to be greater than $k$ convex fuzzy numbers $M_{i}(i=1,2,3, \ldots, k)$ can be defined by equation (9) as:

$$
\begin{gathered}
V\left(M \geq M_{1}, M_{2}, M_{3}, \ldots, M_{k}\right) \\
\quad=V\left[\left(M \geq M_{1}\right) \text { and }\left(M \geq M_{2}\right) \text { and }(M\right. \\
\left.\left.\quad \geq M_{3}\right) \text { and } \ldots \text { and }\left(M \geq M_{k}\right)\right] \\
=\min V\left(M \geq M_{i}\right),(i=1,2,3, \ldots, k)
\end{gathered}
$$

Assuming that equation (9) is expressed as $d^{\prime}\left(A_{i}\right)=$ $\min V\left(S_{i} \geq S_{k}\right)$ for $k=1,2,3, \ldots n ; k \neq i$.

Step 4:

Then, continuing from previous step, the weight priority vectors are obtained using equation (10) as follows:

$W^{\prime}=\left(d^{\prime}\left(A_{1}\right), d^{\prime}\left(A_{2}\right), d^{\prime}\left(A_{3}\right), \ldots, d^{\prime}\left(A_{n}\right)\right)^{T}$

where $A_{i}(i=1,2,3, \ldots n)$ are $n$ elements.

Step 5:

By normalization, the normalized weight vectors are obtained as given in equation (11):

$$
W=\left(d\left(A_{1}\right), d\left(A_{2}\right), d\left(A_{3}\right), \ldots, d\left(A_{n}\right)\right)^{T}
$$

where $W$ is a non-fuzzy number, whose maximum value is 1 . Some well known normalization methods include additive normalization method, weighted least squares method, etc.

\section{Step 6:}

Compare the alternatives for each criterion separately. Produce matrices and weight priority vectors using steps 1 through 5.

Step 7:

Determine the ultimate weights of the alternatives. This is obtained by multiplying the weight vectors derived from the criterion matrix by the weight vectors from the alternatives obtained from step 6 . The alternative with the greatest weight vector value is taken as the best.

\subsection{Weights of Criteria for Academic Staff Selection Using FAHP Model}

The FAHP method was used to model the academic staff selection problem, where experts assign weights to decision criteria using TFNs based on the linguistic variables in the fuzzy conversion scale shown in Table 2. The scale is derived from the work in [25]. The FAHP was developed to tolerate vagueness and uncertainty of human judgment in the selection of best candidate for academic staff employment. Three major criteria were considered for the candidates as shown in the AHP decision hierarchy in figure 5 . In some cases, sub-criteria under major criteria could be considered during evaluation. The criteria considered were:

(i) Academic Qualification $\left(\boldsymbol{C}_{1}\right)$ : Ph.D, M/Phil., M.Sc., M.A., B.Sc., B.A.

In assessing this criterion, it was not assumed that the best candidate was one with a Ph.D degree. Rather, the degree obtained was related to other candidate's quality of research and teaching experience. Also, for others, the grade point average and the class of the degree obtained were considered.

(ii) Research Experience $\left(\boldsymbol{C}_{2}\right)$ : Journal/Conference papers, teaching experience, team work, technical reports, etc.Here, post-qualification teaching experiences as well as number of journal/conference papers published in reputable bodies were highly considered.

(iii) Individual Factor $\left(\boldsymbol{C}_{\mathbf{3}}\right)$ : Age/Compatibility, Selfconfidence/Oral presentation, English Expression, etc.Membership of relevant professional bodies, age and compatibility of applicant in current department was used to assess his/her predicted performance level. Also credit was given to good expressions in English, selfconfidence during oral presentation at interview so as to assess candidate's capability to effectively impact needed knowledge on students. 


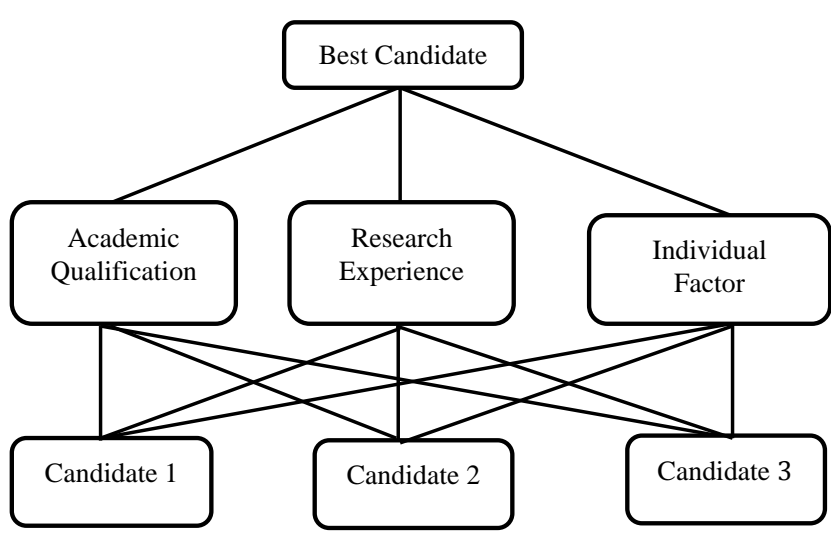

Fig 5: Decision hierarchy

For each alternative, $A_{m}$ the academic qualification, research experience, and individual factor were defined and are shown in the various comparison matrices. The alternative candidates have the following attributes:

Candidate 1( $\left.\mathbf{A}_{\mathbf{1}}\right)$ : The candidate has a B.Sc. degree in relevant field with 2 years working experience in a Polytechnic and is aged 28 years. He has one conference paper and possesses good communication skills. His expression in English is fairly adequate and he is not a member of any professional body.

Candidate 2( $\left.\mathbf{A}_{\mathbf{2}}\right)$ : The candidate is aged 39 years. He has M.Sc. in relevant field with 15 years of teaching and research experience in a university and twenty papers published in local and international reputable journals. $\mathrm{He}$ has 4 international and 6 local conference papers. He also has team leadership qualities with very good expression in English and member of relevant professional bodies.

Candidate $3\left(\mathbf{A}_{3}\right)$ : The candidate is aged 47 years with 6 years of teaching experience in a College of Education. He holds a $\mathrm{Ph} . \mathrm{D}$ degree in relevant field with three local journal and one international conference papers. His oral and written expression in English is adequate and he is a member of the professional body in his discipline.

The developed system architecture for academic staff selection using FAHP model is shown in figure 6 . The system is implemented using Java object-oriented programming software as the frontend development tool while MySQL is used as the backend for database design. Entry of data about alternatives (applicants) and factors (criteria) that influence decision making towards achieving the goal is made through the user interface and stored in the database. First, the criteria by criteria pairwise comparison in a matrix form is carried out following the steps in the FAHP model, and a normalized weight vector is obtained for each criterion. Then, pair-wise comparison of the alternatives is performed for each criterion separately and normalized weight priority vectors are produced. Finally, the ultimate weights of the alternatives are determined by multiplying the weight vectors derived from the criterion matrix by the weight vectors from the alternatives. The alternative with the greatest weight vector value is taken as the best candidate.

The calculations for the selection of the best candidate in line with the steps outlined in section 4 are hereby presented. According to step 1, the criteria matrix was produced by evaluating the criteria according to the fuzzified scale given by [26] as:

\begin{tabular}{|c|c|c|c|}
\hline & $C_{1}$ & $C_{2}$ & $C_{3}$ \\
\hline$C_{1}$ & $1,1,1$ & $\frac{1}{2}, \frac{2}{3}, 1$ & $1, \frac{3}{2}, 2$ \\
\hline$C_{2}$ & $1, \frac{3}{2}, 2$ & $1,1,1$ & $\frac{1}{2}, 1, \frac{3}{2}$ \\
\hline$C_{3}$ & $\frac{1}{2}, \frac{2}{3}, 1$ & $\frac{2}{3}, 1,2$ & $1,1,1$ \\
\hline
\end{tabular}

\section{RESULTS AND DISCUSSION}

Using a specially developed application, according to step 2, the fuzzy synthetic extent values were obtained as follows:

$$
\begin{aligned}
\mathrm{S}_{1}=(2.5,3.17,4.0) & \otimes\left(\frac{1}{12.5}, \frac{1}{9.33}, \frac{1}{7.17}\right) \\
= & (0.2,0.34,0.56) \\
\mathrm{S}_{2}=(2.5,3.5,4.5) & \otimes\left(\frac{1}{12.5}, \frac{1}{9.33}, \frac{1}{7.17}\right) \\
= & (0.2,0.38,0.63) \\
\mathrm{S}_{3}=(2.17,2.67,4.0) & \otimes\left(\frac{1}{12.5}, \frac{1}{9.33}, \frac{1}{7.17}\right) \\
= & (0.17,0.29,0.56)
\end{aligned}
$$

Comparing the fuzzy numbers, the degree of possibility of two TFNs $V\left(S_{1} \geq S_{2}\right)$ was obtained according to step 3 . The calculated values for the degree of possibility of superiority for the first criteria are:

$$
\mathrm{V}\left(\mathrm{S}_{1} \geq \mathrm{S}_{2}\right)=0.9 \quad \mathrm{~V}\left(\mathrm{~S}_{1} \geq \mathrm{S}_{3}\right)=1
$$

For the second criteria, the values are calculated as:

$$
\mathrm{V}\left(\mathrm{S}_{2} \geq \mathrm{S}_{1}\right)=1 \quad \mathrm{~V}\left(\mathrm{~S}_{2} \geq \mathrm{S}_{3}=1\right)
$$

For the third criteria, the values are calculated as:

$\mathrm{V}\left(\mathrm{S}_{3} \geq \mathrm{S}_{1}\right)=0.88 \quad \mathrm{~V}\left(\mathrm{~S}_{3} \geq \mathrm{S}_{2}\right)=0.8$

Then, the minimum degree of possibility of superiority of each criterion over another is obtained, as described in step 3, which gives the weight priority vectors of the criteria, defined in step 4, as:

$\mathrm{W}^{\prime}=(0.9,1,0.8)$

The normalized weight of this vector describes the priority weight of each criterion over another. It indicates that the second criterion (research experience) has higher priority than the other criteria. The normalized weight vectors are calculated as:

$\mathrm{W}=(0.33,0.37,0.3)$

The criteria-based evaluation of alternatives (considering 3 alternatives for simplicity) and the normalized weight for each comparison, according to step 6 , is shown next.

\section{Criterion 1}

The comparison matrix for alternatives with regards to the first criterion is given as: 


$$
\mathrm{X}_{\mathrm{C}_{1}}=
$$

\begin{tabular}{|c|c|c|c|}
\hline $\mathrm{C}_{1}$ & $\mathrm{~A}_{1}$ & $\mathrm{~A}_{2}$ & $\mathrm{~A}_{3}$ \\
\hline $\mathrm{A}_{1}$ & $1,1,1$ & $3,4,5$ & $\frac{1}{9}, \frac{1}{8}, \frac{1}{7}$ \\
\hline $\mathrm{A}_{2}$ & $\frac{1}{5}, \frac{1}{4}, \frac{1}{3}$ & $1,1,1$ & $5,6,7$ \\
\hline $\mathrm{A}_{3}$ & $7,8,9$ & $\frac{1}{7}, \frac{1}{6}, \frac{1}{5}$ & $1,1,1$ \\
\hline
\end{tabular}

The fuzzy synthetic extent values are:

$\mathrm{S}_{1} \mathrm{C}_{1}=(0.17,0.24,0.33)$,

$\mathrm{S}_{2} \mathrm{C}_{2}=(0.25,0.34,0.45)$,

$\mathrm{S}_{3} \mathrm{C}_{3}=(0.33,0.43,0.55)$

The degree of possibility of one alternative over the others is given as:

$\mathrm{V}_{\mathrm{C}_{1}}\left(\mathrm{~S}_{1} \geq \mathrm{S}_{2}\right)=0.44$

$\mathrm{V}_{\mathrm{C}_{1}}\left(\mathrm{~S}_{1} \geq \mathrm{S}_{3}\right)=0$

$\mathrm{V}_{\mathrm{C}_{1}}\left(\mathrm{~S}_{2} \geq \mathrm{S}_{1}\right)=1$

$\mathrm{V}_{\mathrm{C}_{1}}\left(\mathrm{~S}_{2} \geq \mathrm{S}_{3}\right)=0.52$

$\mathrm{V}_{\mathrm{C}_{1}}\left(\mathrm{~S}_{3} \geq \mathrm{S}_{1}\right)=1$

$\mathrm{V}_{\mathrm{C}_{1}}\left(\mathrm{~S}_{3} \geq \mathrm{S}_{2}\right)=1$

The weight priority vectors and the normalized weight values are:

$\mathrm{W}^{\prime}=(0,0.52,1)$

$\mathrm{W}=(0,0.34,0.66)$

Criterion 2

The comparison matrix for alternatives with regards to the second criterion is given as:

$$
\mathrm{X}_{\mathrm{C}_{2}}=
$$

\begin{tabular}{|c|c|c|c|}
\hline $\mathrm{C}_{2}$ & $\mathrm{~A}_{1}$ & $\mathrm{~A}_{2}$ & $\mathrm{~A}_{3}$ \\
\hline $\mathrm{A}_{1}$ & $1,1,1$ & $3,4,5$ & $\frac{1}{7}, \frac{1}{6}, \frac{1}{5}$ \\
\hline $\mathrm{A}_{2}$ & $\frac{1}{5}, \frac{1}{4}, \frac{1}{3}$ & $1,1,1$ & $7,8,9$ \\
\hline $\mathrm{A}_{3}$ & $5,6,7$ & $\frac{1}{9}, \frac{1}{8}, \frac{1}{7}$ & $1,1,1$ \\
\hline
\end{tabular}

The fuzzy synthetic extent values are:

$\mathrm{S}_{1} \mathrm{C}_{2}=(0.17,0.24,0.34)$

$\mathrm{S}_{3} \mathrm{C}_{2}=(0.25,0.33,0.44)$

$\mathrm{S}_{2} \mathrm{C}_{2}=(0.33,0.43,0.56)$,

The degree of possibility of one alternative over the others is given as:

$\mathrm{V}_{\mathrm{C}_{2}}\left(\mathrm{~S}_{1} \geq \mathrm{S}_{2}\right)=0.05$

$\mathrm{V}_{\mathrm{C}_{2}}\left(\mathrm{~S}_{1} \geq \mathrm{S}_{3}\right)=0.5$

$\mathrm{V}_{\mathrm{C}_{2}}\left(\mathrm{~S}_{2} \geq \mathrm{S}_{1}\right)=1$

$\mathrm{V}_{\mathrm{C}_{2}}\left(\mathrm{~S}_{2} \geq \mathrm{S}_{3}\right)=1$

$\mathrm{V}_{\mathrm{C}_{2}}\left(\mathrm{~S}_{3} \geq \mathrm{S}_{1}\right)=1$

$\mathrm{V}_{\mathrm{C}_{1}}\left(\mathrm{~S}_{3} \geq \mathrm{S}_{2}\right)=0.52$

The weight priority vectors and the normalized weight values are:

$\mathrm{W}^{\prime}=(0.05,1,0.52)$

$\mathrm{W}=(0.03,0.64,0.33)$

\section{Criterion 3}

The comparison matrix for alternatives with regards to the third criterion is given as:

$$
\mathrm{X}_{\mathrm{C}_{3}}=
$$

\begin{tabular}{|c|c|c|c|}
\hline $\mathrm{C}_{3}$ & $\mathrm{~A}_{1}$ & $\mathrm{~A}_{2}$ & $\mathrm{~A}_{3}$ \\
\hline $\mathrm{A}_{1}$ & $1,1,1$ & $1,2,3$ & $\frac{1}{7}, \frac{1}{6}, \frac{1}{5}$ \\
\hline $\mathrm{A}_{2}$ & $\frac{1}{3}, \frac{1}{2}, 1$ & $1,1,1$ & $7,8,9$ \\
\hline $\mathrm{A}_{3}$ & $5,6,7$ & $\frac{1}{9}, \frac{1}{8}, \frac{1}{7}$ & $1,1,1$ \\
\hline
\end{tabular}

The fuzzy synthetic extent values are:

$\mathrm{S}_{1} \mathrm{C}_{3}=(0.09,0.16,0.25)$,

$\mathrm{S}_{2} \mathrm{C}_{3}=(0.36,0.48,0.66)$,

$\mathrm{S}_{3} \mathrm{C}_{3}=(0.26,0.36,0.49)$

The degree of possibility of one alternative over the others is given as:

$\mathrm{V}_{\mathrm{C}_{3}}\left(\mathrm{~S}_{1} \geq \mathrm{S}_{2}\right)=0$

$\mathrm{V}_{\mathrm{C}_{3}}\left(\mathrm{~S}_{1} \geq \mathrm{S}_{3}\right)=0$

$\mathrm{V}_{\mathrm{C}_{3}}\left(\mathrm{~S}_{2} \geq \mathrm{S}_{1}\right)=1$

$\mathrm{V}_{\mathrm{C}_{3}}\left(\mathrm{~S}_{2} \geq \mathrm{S}_{3}\right)=1$

$\mathrm{V}_{3}\left(\mathrm{~S}_{3} \geq \mathrm{S}_{1}\right)=1$

$\mathrm{V}_{3}\left(\mathrm{~S}_{3} \geq \mathrm{S}_{2}\right)=0.52$

The weight priority vectors and the normalized weight values are as:

$\mathrm{W}^{\prime}=(0,1,0.52)$

$\mathrm{W}=(0,0.66,0.34)$

Finally, the ultimate weights of the alternatives are determine, according to step 7 , as shown on Table 3 . The criteria-based evaluation indicates that alternative 2 gives the highest priority weight and therefore the second candidate is the best selected or most suitable for employment while the first candidate is the least ranked due to its smallest weight. Figure 7 shows the Java implemented results of normalized weight vector for each criteria and the criteria-based normalized weight vector for each alternative while figure 8 shows the

\begin{tabular}{|c|c|c|c|c|}
\hline Criterion & $\begin{array}{l}\text { Criterion } \\
\text { weight }\end{array}$ & $\mathbf{A}_{1}$ weight & $\mathbf{A}_{2}$ weight & A 3 weight \\
\hline 1 & 0.33 & 0 & 0.34 & 0.66 \\
\hline 2 & 0.37 & 0.03 & 0.64 & 0.33 \\
\hline 3 & 0.30 & 0 & 0.66 & 0.34 \\
\hline \multicolumn{2}{|c|}{ Final weight } & 0.01 & 0.55 & 0.44 \\
\hline \multicolumn{2}{|c|}{ Ranking } & 3 & 1 & 2 \\
\hline
\end{tabular}
final (ultimate) weight and ranking of each alternative.

Table 3. Final evaluation of alternatives based on weight 


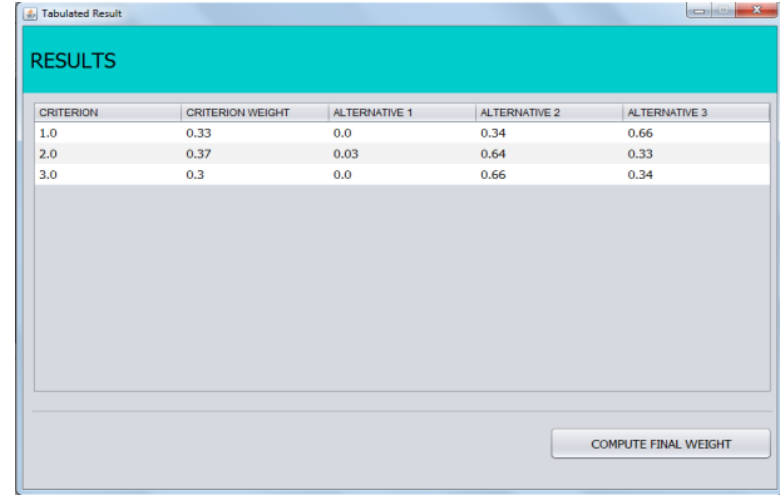

Fig 7: Normalized weight vector

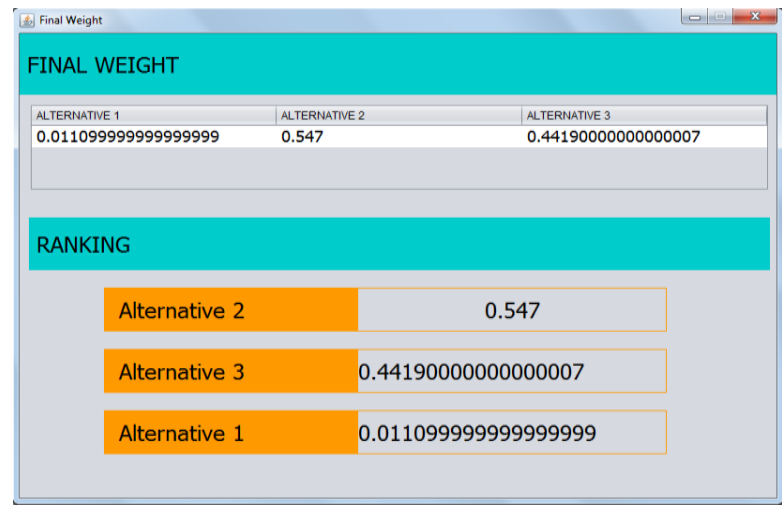

Fig 8: Final weight and ranking of alternatives

\section{CONCLUSION}

In this paper, a detailed numerical example illustrating the application of FAHP model to a university academic staff selection problem was given. The AHP technique could only make a best selection decision by using weighting process for a set of alternatives through pair-wise comparison. The inability of AHP to deal with imprecision and subjectivity in the pair-wise comparison process has been improved in the fuzzy AHP model. Our fuzzy AHP approach proves to be a more useful tool for solving multi-criteria decision problems with inherent uncertainty and deviations in DM's opinions. The vagueness in human opinion is captured and synthesized using TFNs and Chang's extent analysis to identify the weight of each criterion. The weights represent the ratio of how much more important one alternative is than another, with respect to the goal or criterion at a higher level. The alternatives were ranked and the best candidate was taken to be the one with the highest normalized priority weight. This approach and the proposed system design can be practically employed in the recruitment process of other organizations with highly accurate results.

\section{REFERENCES}

[1] Rouyendegh, B. D. and Erkan, T. E. 2012. Selection of Academic Staff using the Fuzzy Analytical Hierarchy Process (FAHP): A Pilot Study, Tehnicki vjesnik, 19(4), 923-929.

[2] Mollaghasemi, M. 1997 Decisions, IEEE, California.

[3] Mendoza, G.A. and Martins, H. 2006. Multi-criteria decision analysis in natural resource management: A critical review of methods and new modeling paradigms, Forest Ecology and Management, 230 (1-3), 1-22.
[4] Ribeiro, R. A. 1996. Fuzzy multiple criterion decision making: A review and new preference elicitation techniques, Fuzzy Sets and Systems,78, 155-181.

[5] Kabir, G. and Hasin, M. A. A. 2011. Comparative analysis of AHP and fuzzy AHP models for multicriteria inventory classification, International Journal of Fuzzy Logic Systems, 1(1), (October, 2011), 1-16.

[6] Mahendran, P., Moorthy, M. B. K. and Saravanan, S. 2014. A fuzzy AHP approach for selection of measuring instrument for engineering college selection, Applied Mathematical Sciences, 8(44), 2149 - 2161.

[7] Singh A.P., Ghosh S.K. and Sharma, P. 2007. Water quality management of a stretch of river Yamuna: An interactive fuzzy multi-objective approach, Water Resource Management, 21,515-532.

[8] Bajić, D. and Polomčić, D. 2014. Fuzzy optimization in hydrodynamic analysis of groundwater control systems: case study of the pumping station "Bezdan 1", Serbia, Annales Geologiques de la Peninsule Balkanique, 75, (December, 2014), 103-110.

[9] Mikhailov, L. and Tsvetinov, P. 2004. Evaluation of Services using a fuzzy analytic hierarchy process, Applied Soft Computing, 5, 23-33.

[10] Dubey, S. K., Mittal, A. and Rana, A. 1998. Measurement of object oriented software usability using fuzzy AHP, International Journal of Computer Science and Telecommunications, 3(5), 98-104.

[11] Liang, S. and Wang, M. J. J. 1994. Personnel selection using fuzzy MCDM algorithm, European Journal of Operational Research, 78, 22-33.

[12] Asuquo, D. E. and Umoh, U. A. 2015. Analytic hierarchy process for QoS evaluation of mobile data networks, International Journal of Computer Networks and Communications, 7(6), (November, 2015), 125-137.

[13] Saaty, T.L. 1980. The Analytic Hierarchy Process: Planning, Priority Setting, Resource Allocation, McGraw-Hill, New York.

[14] Saaty, T. L. 2008. Decision Making with the Analytic Hierarchy Process, International Journal of Services Sciences, 1(1), 83-98.

[15] Zadeh, L. A. 1965. Fuzzy Sets. Information and Control, $8,338-353$.

[16] Zadeh, L.A. 1975. The Concept of a Linguistic Variable and its Application to Approximate Reasoning, Information Sciences, 8, 199-249.

[17] Shu, M. S., Cheng, C. H. and Chang, J. R. 2006. Using Intuitionistic Fuzzy Set for Fault-tree Analysis on Printed Circuit Board Assembly, Microelectronics Reliability, 46 (12), 2139-2148.

[18] Zhu, K. J., Jing, Y. and Chang, D. Y., 1999. A Discussion on Extent Analysis Method and Applications of Fuzzy AHP, European Journal of Operational Research, 116(2), 4450-456.

[19] van Laarhoven, P. J. M. and Pedrycz, W. 1983. A fuzzy Extension of Saaty's Priority Theory, Fuzzy Sets and Systems, 11, 229-241.

[20] Buckley, J. J. 1985. Fuzzy Hierarchical Analysis, Fuzzy Sets and Systems, 17(3), 233-247. 
[21] Chang, D. Y. 1996. Applications of the Extent Analysis Method on Fuzzy AHP, European Journal of Operational Research, 95(3), 649-655.

[22] Xu, R., 2006. Fuzzy Least Square Priority Method in the Analytic Hierarchy Process, Fuzzy Sets and Systems, 112(3), 395-404.

[23] Mikhailov, L. 2003. Deriving Priorities from Fuzzy Pairwise Comparison Judgements, Fuzzy Sets and Systems, 134(3), 365-385.

[24] Wang, Y. M., Yang, J. B. and Xu, D. L. 2005. A Twostage Logarithmic Goal Programming Method for Generating Weights from Interval Comparison Matrices, Fuzzy Sets Systems, 152, 475-498.
[25] Deng, H. 1999. Multicriteria Analysis with Fuzzy Pairwise Comparisons, International Journal of Approximate Reasoning, 21, 215-231.

[26] Tolga, E., Demircan, M. L. and Kahraman, C. 2005. Operating System Selection Using Fuzzy Replacement Analysis and Analytic Hierarchy Process, International Journal of Production Economics, 97, 89-117.

[27] Chang, D. Y. 1992. Extent Analysis and Synthetic Decision Optimization Techniques and Applications, vol.1, World Scientific, Singapore, 352.

[28] Bozbura, F. T., Beskese, A., and Kahraman, C. 2007. Prioritization of Human Capital Measurement Indicators using FAHP, Expert Systems with Applications, 32(4), $1100-1112$

\section{APPENDIX}

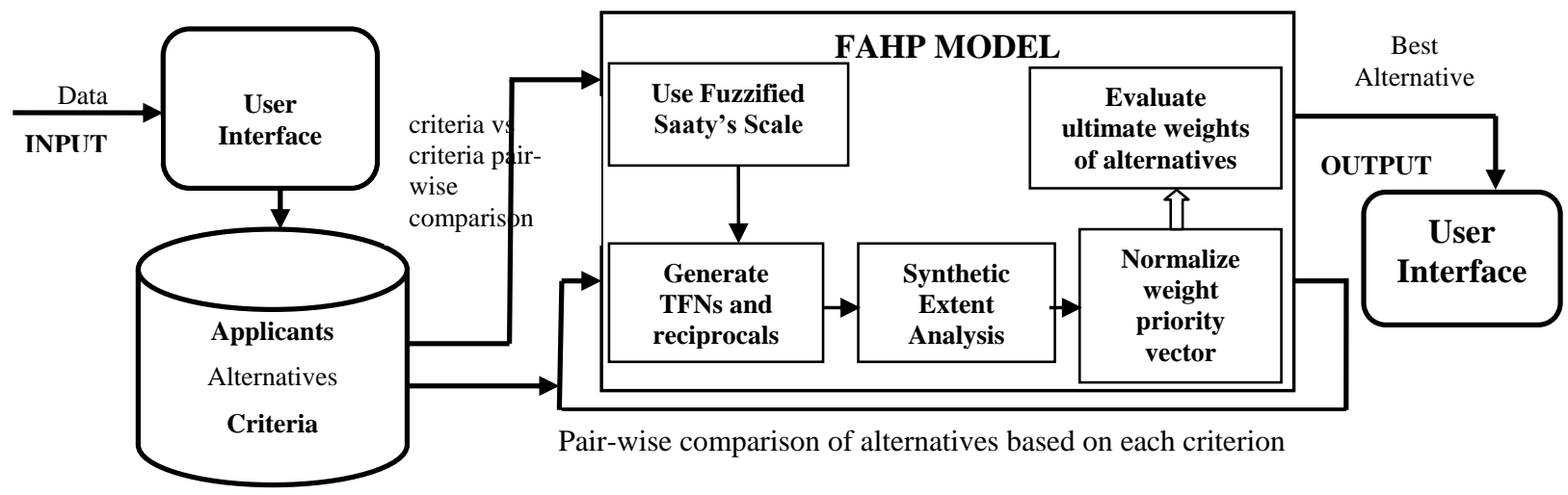

Fig 6: System Architecture for problem solving using FAHP Model 